Lina Zgaga, Susan M. Farrington, Farhat V.N. Din, Li Yin Ooi, Dominik Glodzik, Albert Tenesa, Harry Campbell, and Malcolm G. Dunlop, University of Edinburgh and Western General Hospital; Evropi Theodoratou and Harry Campbell, University of Edinburgh, Edinburgh; Albert Tenesa, University of Edinburgh, Roslin; Susan Johnston, Glasgow Royal Infirmary, Glasgow, United Kingdom; Lina Zgaga, Trinity College Dublin, Dublin, Ireland.

Published online ahead of print at www.jco.org on July 7, 2014.

Supported by Programme Grant No. C348/A12076 from Cancer Research UK, by Project Grant No. CZH/4/529 from the Chief Scientist Office, and by Cancer Research UK Clinician Scientist Fellowship No. C26031/A11378 (F.V.N.D.).

L.Z. and E.T. contributed equally to this work.

Terms in blue are defined in the glossary, found at the end of this article and online at www.jco.org.

Authors' disclosures of potential conflicts of interest and author contributions are found at the end of this article.

Corresponding author: Malcolm G Dunlop, MD, Medical Research Council Human Genetics Unit, Institute of Genetics and Molecular Medicine, University of Edinburgh, Western General Hospital, Edinburgh EH4 2XU, United Kingdom; e-mail: malcolm.dunlop@igmm.ed.ac.uk.

(ㄷ) 2014 by American Society of Clinical Oncology

0732-183X/14/3223w-2430w/\$20.00 DOI: $10.1200 / J C O .2013 .54 .5947$

\title{
Plasma Vitamin D Concentration Influences Survival Outcome After a Diagnosis of Colorectal Cancer
}

Lina Zgaga, Evropi Theodoratou, Susan M. Farrington, Farhat V.N. Din, Li Yin Ooi, Dominik Glodzik, Susan Johnston, Albert Tenesa, Harry Campbell, and Malcolm G. Dunlop

$$
\begin{array}{llllllll}
\text { A } & \text { B } & \text { S } & \text { T } & \text { R } & \text { A } & \text { C } & \text { T }
\end{array}
$$

\section{Purpose}

We investigated whether the plasma level of 25-hydroxyvitamin D (25-OHD) after a diagnosis of colorectal cancer (CRC) influences survival outcome.

\section{Patients and Methods}

We prospectively studied 1,598 patients with stage I to III CRC. We sought association between plasma 25-OHD and stage-specific survival and tested for interaction between 25-OHD level and variation at the vitamin $D$ receptor (VDR) gene locus. Blood was sampled postoperatively, and plasma was assayed for 25-OHD by liquid chromatography-tandem mass spectrometry. VDR polymorphisms (rs1544410, rs10735810, rs7975232, rs11568820) were genotyped, and haplotypes were inferred by using BEAGLE software. We tested for association between survival and 25-OHD, VDR genotype/haplotype, and after applying a VDR genotype-25-OHD interaction term. We conducted Kaplan-Meier survival analysis and used Cox proportional hazards models to estimate adjusted hazard ratios (HRs).

\section{Results}

We found strong associations between plasma 25-OHD concentration and CRC-specific $(P=.008)$ and all-cause mortality $(P=.003)$. Adjusted HRs were $0.68(95 \% \mathrm{Cl}, 0.50$ to 0.90$)$ and $0.70(95 \%$ $\mathrm{Cl}, 0.55$ to 0.89 ), respectively (highest $v$ lowest $25-\mathrm{OHD}$ tertile), particularly in stage II disease (HR, $0.44 ; P=.004$ for $\mathrm{CRC}$-specific mortality). We detected gene-environment interactions between 25-OHD concentration and rs11568820 genotype for CRC-specific $(P=.008)$ and all-cause $(P=$ .022) mortality, number of protective alleles $(P=.004$ and $P=.018$, respectively), and GAGC haplotype at the VDR locus for all-cause mortality $(P=.008)$.

\section{Conclusion}

In patients with stage I to III CRC, postoperative plasma vitamin D is associated with clinically important differences in survival outcome, higher levels being associated with better outcome. We observed interactions between 25-OHD level and VDR genotype, suggesting a causal relationship between vitamin $D$ and survival. The influence of vitamin $D$ supplementation on $C R C$ outcome will require further investigation.

\section{J Clin Oncol 32:2430-2439. (C) 2014 by American Society of Clinical Oncology}

\section{INTRODUCTION}

Vitamin D deficiency is implicated in the etiology of several common diseases, including cancer. ${ }^{1}$ Colorectal cancer (CRC) is the third most frequent cancer worldwide, with an estimated 1.2 million cases or more and 600,000 deaths annually, and yet it is potentially largely preventable. ${ }^{2}$ Worldwide, there is substantial variation in CRC incidence (10-fold) and mortality (six-fold $)^{2}$ that may be attributable to different vitamin D levels between populations. ${ }^{3}$

Dietary vitamin D intake is generally low, even in those taking supplements. ${ }^{4,5}$ Hence, skin synthesis during exposure to sunlight (ultraviolet B) is the major source of vitamin D. Such synthesis is pro- foundly influenced by geographical latitude and meteorologic factors. Modern lifestyle further compounds any deficit, because daylight hours are increasingly spent indoors. Thus, maintaining sufficient vitamin D levels is severely compromised, particularly in northern latitudes.

Establishing a causal relationship between CRC incidence and vitamin D deficiency is challenging because environmental risk factors associated with CRC may also be associated with vitamin D deficiency (co-causality; eg, level of physical activity), the presence of a tumor and its treatment may actually deplete vitamin $\mathrm{D}$ (reverse causation): decreased circulating 25-hydroxyvitamin D (25$\mathrm{OHD})$ concentration has been reported after 


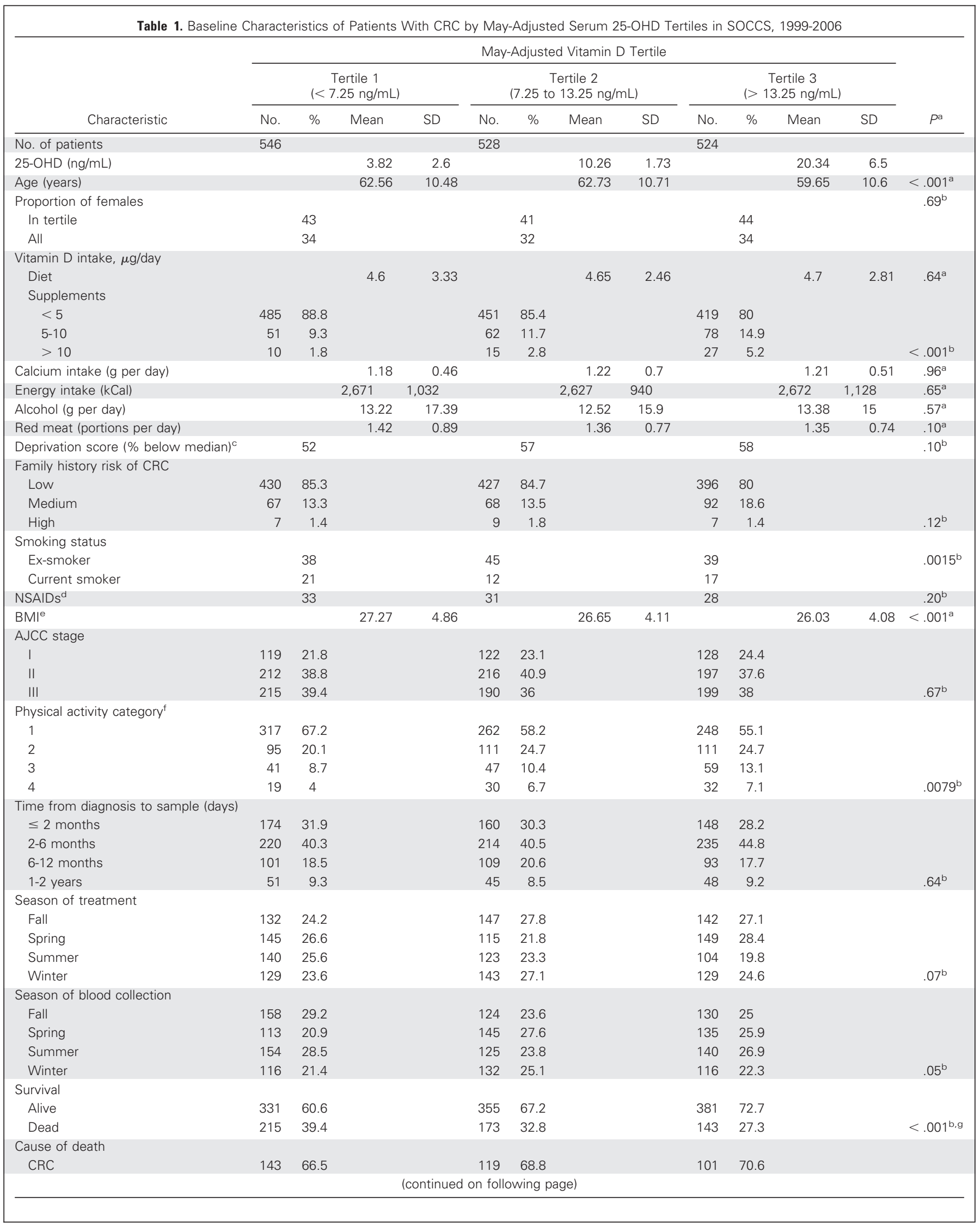




\begin{tabular}{|c|c|c|c|c|c|c|c|c|c|c|c|c|c|}
\hline \multirow[b]{3}{*}{ Characteristic } & \multicolumn{12}{|c|}{ May-Adjusted Vitamin D Tertile } & \multirow[b]{3}{*}{$P^{a}$} \\
\hline & \multicolumn{4}{|c|}{$\begin{array}{c}\text { Tertile } 1 \\
(<7.25 \mathrm{ng} / \mathrm{mL})\end{array}$} & \multicolumn{4}{|c|}{$\begin{array}{c}\text { Tertile } 2 \\
\text { (7.25 to } 13.25 \mathrm{ng} / \mathrm{mL})\end{array}$} & \multicolumn{4}{|c|}{$\begin{array}{c}\text { Tertile } 3 \\
(>13.25 \mathrm{ng} / \mathrm{mL})\end{array}$} & \\
\hline & No. & $\%$ & Mean & SD & No. & $\%$ & Mean & SD & No. & $\%$ & Mean & SD & \\
\hline Other cause & 45 & 20.9 & & & 32 & 18.5 & & & 25 & 17.5 & & & \\
\hline Other cancer & 24 & 11.2 & & & 20 & 11.6 & & & 17 & 11.9 & & & $.93^{\mathrm{b}, \mathrm{h}}$ \\
\hline Unknown & 3 & 1.4 & & & 2 & 1.2 & & & 0 & 0 & & & \\
\hline \multicolumn{14}{|c|}{ 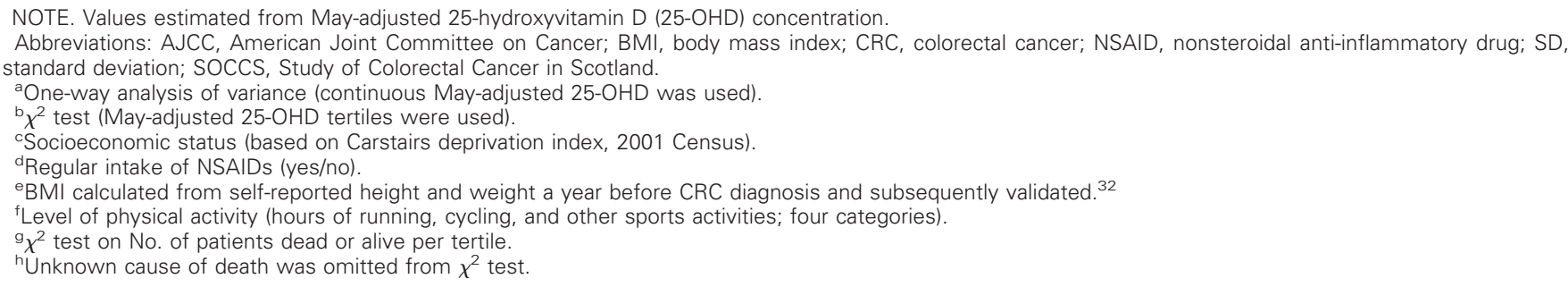 } \\
\hline
\end{tabular}

elective knee surgery, ${ }^{6}$ and voluntary or involuntary changes in a patient's diet and lifestyle, such as being bed-bound or suffering fatigue, may decrease time spent outdoors and have further impact on 25-OHD levels. Evidence from studies investigating the relationship between CRC risk and exposure to solar radiation and vitamin $\mathrm{D}$ intake and/or circulating levels supports an inverse relationship between vitamin $\mathrm{D}$ and risk. ${ }^{7,8}$ Moreover, interaction between vitamin $\mathrm{D}$ level and functional sequence variants at the vitamin D receptor (VDR) gene locus also influence CRC risk. ${ }^{9,10}$

The relationship between vitamin D and CRC mortality is even less well understood. An ecological study published more than 30 years ago was the first to report an inverse relationship between CRC mortality and exposure to solar radiation. ${ }^{11}$ Similarly, better survival in patients diagnosed during summer and fall was shown more recently. ${ }^{12}$ These provide circumstantial evidence linking vitamin D levels with cancer outcome. Higher intake of dietary vitamin $\mathrm{D}^{13}$ and higher circulating levels of $25-\mathrm{OHD}^{13-17}$ have also been linked to better survival after CRC diagnosis. However, published work used proxies for plasma vitamin D level in patients with cancer (season of diagnosis, ultraviolet $B$ intensity, dietary vitamin D). Prediagnostic plasma 25-OHD level that has been associated with cancer survival seems unlikely to reflect vitamin D level in the period following diagnosis, surgery, and chemotherapy. Predicted vitamin D level at diagnosis (from assays performed years before diagnosis) also suggests an association between low levels and poor CRC survival outcome. ${ }^{16}$

In this study, we investigated whether circulating vitamin $\mathrm{D}$ concentration influences survival after surgical intervention for CRC. We directly assayed total 25-OHD, which reflects both dietary intake and skin synthesis of vitamin D. ${ }^{18,19}$ To mitigate against potential confounding effects due to reverse causation, thereby implicating a causal relationship, we tested for interaction between plasma vitamin $\mathrm{D}$ level and genotype at the $V D R$ locus.

\section{PATIENTS AND METHODS}

\section{Study Population and Follow-Up}

The Study of Colorectal Cancer in Scotland (SOCCS) is a prospective, population-based case-control study designed to identify genetic and environ- mental factors that have an impact on CRC risk and survival outcome. ${ }^{20}$ All participants provided informed written consent, and research was approved by the MultiCentre Research Ethics Committee for Scotland, local research ethics committees, and National Health Service management. In this study, we measured 25-OHD plasma levels in 1,598 patients with stage I to III CRC who underwent surgical resection with curative intent and for whom we collected detailed clinical, pathologic, dietary, and lifestyle information.

Follow-up was through systematic search of the Scottish national records system. Deaths were ascertained through linkage to National Records of Scotland. Primary cause of death (CRC, other cancer, other cause) was assigned from death certificates separately by two researchers (L.Z., F.V.N.D; > 99\% concordance). Follow-up was calculated as time between blood sampling and death or between sampling and censor date (January 31, 2013) for patients who were not known to have died.

\section{Plasma Vitamin D Assay}

To minimize technical variability, all plasma samples were batched, and 25-OHD was assayed to a standardized protocol in the same laboratory. Total $25-\mathrm{OHD}\left(25-\mathrm{OHD}_{2}\right.$ and $\left.25-\mathrm{OHD}_{3}\right)$ was measured by liquid chromatographytandem mass spectrometry. ${ }^{21}$ To account for seasonal differences, 25-OHD concentration was May-standardized by adjusting for sampling month using differences in age- and sex-adjusted monthly averages generated from SOCCS control participants. ${ }^{4}$ May-adjusted measurements were used in analyses throughout, unless otherwise specified.

Vitamin D deficiency is defined in terms of circulating 25-OHD as vitamin $\mathrm{D}$ deficient $(<10 \mathrm{ng} / \mathrm{mL}$ ), at high (10 to $16 \mathrm{ng} / \mathrm{mL}$ ) or low (16 to 20 $\mathrm{ng} / \mathrm{mL}$ ) risk of deficiency, or as vitamin D sufficient $(>20 \mathrm{ng} / \mathrm{mL})$, although these thresholds are subject to debate. ${ }^{4,18}$ Because few individuals in Scotland are vitamin D sufficient, ${ }^{4}$ we grouped patients into $25-\mathrm{OHD}$ tertiles to maximize statistical power. Vitamin D intake was calculated from a food frequency questionnaire. ${ }^{4}$

\section{Genotype at the VDR Locus}

Blood leukocyte DNA was genotyped for polymorphisms at the VDR gene locus (rs1544410, rs10735810, rs7975232, rs11568820) by using either an Illumina Infinium array or DNA sequencing. Protective allele score was calculated by summing the following: rs $10735810 \mathrm{G}$ allele, ${ }^{22}$ a variant that determines the translational start site and downstream 1,25dihydroxycholecalciferol $\left(1,25[\mathrm{OH}]_{2} \mathrm{D}\right)$ effects $^{23}$; rs1544410 $\mathrm{T}$ allele, a variant that has been associated with increased VDR mRNA expression and increased serum levels of $1,25(\mathrm{OH})_{2} \mathrm{D}^{24}$; and rs11568820 A allele, a variant that is located in the $V D R$ promoter region and directly influences transcriptional activity. ${ }^{25}$ rs7975232 has been excluded, given high correlation with $\mathrm{rs} 1544410\left(r^{2}=0.63\right.$ in the United Kingdom; $\chi^{2} P<.001$ in this cohort). We estimated $V D R$ phased haplotypes for the four genotyped $V D R$ 


\begin{tabular}{|c|c|c|c|c|c|c|c|c|c|}
\hline \multirow[b]{3}{*}{ Model } & \multirow{3}{*}{$\begin{array}{c}\text { Tertile } 1 \\
(<7.25 \mathrm{ng} / \mathrm{mL})\end{array}$} & \multicolumn{6}{|c|}{ Vitamin D Tertiles (May-adjusted 25-OHD) } & \multirow[b]{3}{*}{$P_{\text {trend }}$} & \multirow{3}{*}{$\begin{array}{l}\text { No. of } \\
\text { Patients }\end{array}$} \\
\hline & & \multicolumn{3}{|c|}{$\begin{array}{c}\text { Tertile } 2 \\
(7.25-13.25 \mathrm{ng} / \mathrm{mL}) \\
\end{array}$} & \multicolumn{3}{|c|}{$\begin{array}{c}\text { Tertile } 3 \\
(>13.25 \mathrm{ng} / \mathrm{mL})\end{array}$} & & \\
\hline & & $\mathrm{HR}$ & $95 \% \mathrm{Cl}$ & $P$ & $\mathrm{HR}$ & $95 \% \mathrm{Cl}$ & $P$ & & \\
\hline \multicolumn{10}{|l|}{$\overline{\text { CRC mortality* }}$} \\
\hline Unadjusted & Ref & 0.8 & 0.63 to 1.02 & .08 & 0.66 & 0.51 to 0.85 & .001 & .0012 & 1,594 \\
\hline Adjusted $†$ & Ref & 0.81 & 0.63 to 1.03 & .09 & 0.67 & 0.52 to 0.87 & .002 & .002 & 1,573 \\
\hline Fully adjusted $¥$ & Ref & 0.86 & 0.66 to 1.13 & .27 & 0.68 & 0.50 to 0.90 & .008 & .009 & 1,336 \\
\hline \multicolumn{10}{|c|}{ All-cause mortality* } \\
\hline Unadjusted & Ref & 0.78 & 0.64 to 0.95 & .01 & 0.62 & 0.5 to 0.77 & $<.001$ & $<.001$ & 1,598 \\
\hline Adjusted $t$ & Ref & 0.77 & 0.63 to 0.94 & .01 & 0.66 & 0.53 to 0.81 & $<.001$ & $<.001$ & 1,577 \\
\hline Fully adjusted $¥$ & Ref & 0.81 & 0.65 to 1.01 & .056 & 0.70 & 0.55 to 0.89 & .0034 & .0029 & 1,338 \\
\hline \multicolumn{10}{|c|}{ 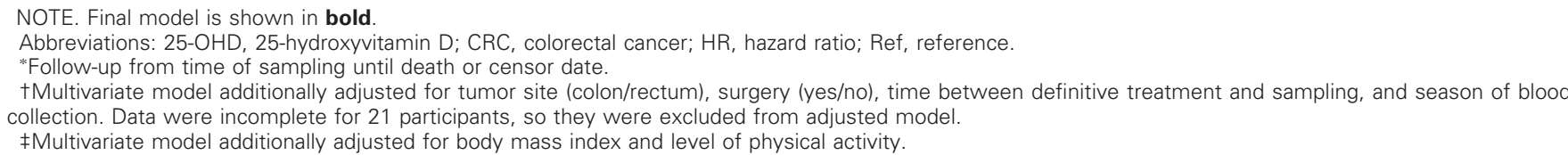 } \\
\hline
\end{tabular}

polymorphisms for all samples by using BEAGLE software (version 3.3.2) with standard settings. ${ }^{26}$ BEAGLE builds a model of haplotypes from which it identifies likely haplotypes that underlie the genotype data. The resulting haplotypes were tabulated so that each sample was assigned two haplotypes. Accordingly, variables corresponding to the dose of each haplotype were created. For each haplotype, we set the dose to give values of 0 (haplotype not present), 1 (heterozygous), or 2 (homozygous), with the sum of haplotype doses equaling 2 for any individual.

Given sample size constraints, we considered only haplotypes with frequencies of more than $10 \%$ and included them as dose variables in the adjusted Cox proportional hazards regression models (rarer haplotypes were ignored). We first ran models that investigated main effects of VDR haplotypes and then extended the models to include interaction terms between VDR haplotypes and May-adjusted vitamin D tertiles.

\section{Patient- and Tumor-Related Variables}

We considered factors with an established contribution to CRC mortality or etiology, including sex; smoking; physical activity; family history; non- steroidal anti-inflammatory drugs; total daily energy; red meat, calcium, and alcohol intake; and socioeconomic status. ${ }^{20}$ We collected detailed information on tumor site and multiplicity and clinicopathologic staging from clinical records and tumor boards (Scottish Managed Clinical Networks). Preoperative imaging was collected from participating centers. By using collated pathology, imaging, and clinical data, tumor stage was assigned according to the Union for International Cancer Control TNM staging system and was mapped onto the American Joint Committee on Cancer (AJCC) staging system (AJCC stage I to IV). AJCC stage IV was excluded from the analysis of vitamin D effect on survival.

\section{Surgery and Chemotherapy}

Date of definitive treatment is the date of surgical treatment. Extent of surgery was recorded (as polypectomy and/or local excision or resection). All patients were treated with curative intent, so any chemotherapy was administered in the adjuvant setting. We assessed whether chemotherapy modified associations between 25-OHD concentration and mortality in stage II and III

Table 3. Unadjusted and Multivariable Adjusted HRs of CRC-Specific Death According to May-Adjusted 25-OHD Tertile and AJCC Cancer Stage

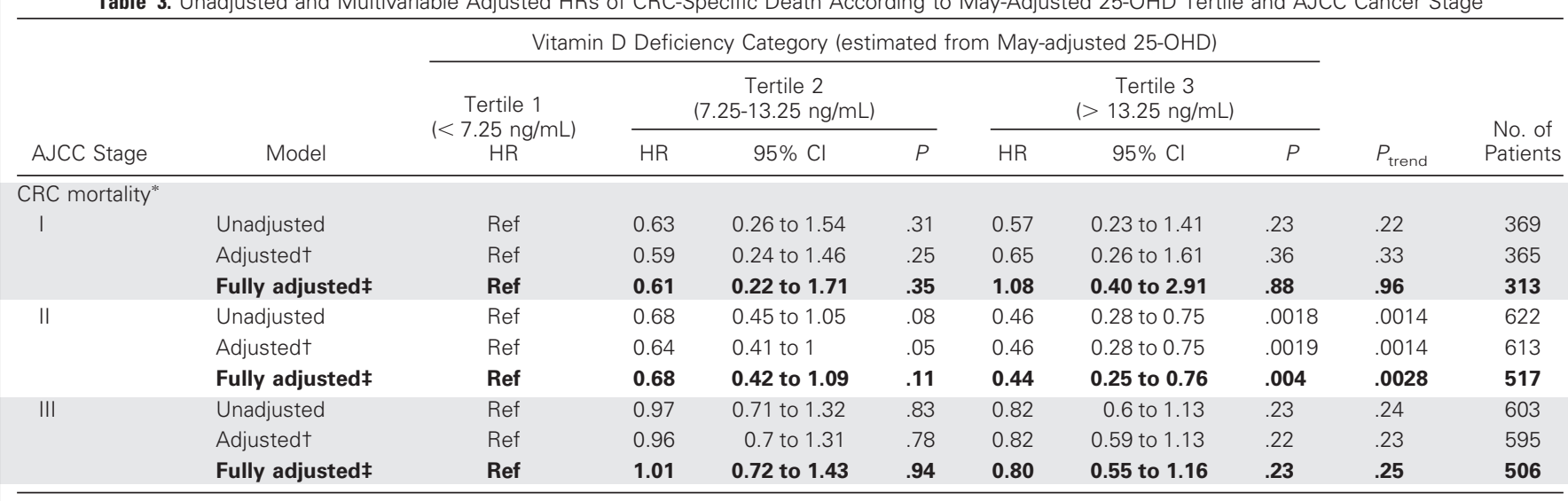

NOTE. Final model is shown in bold.

Abbreviations: 25-OHD, 25-hydroxyvitamin D; AJCC, American Joint Committee on Cancer; CRC, colorectal cancer; HR, hazard ratio.

*Follow-up from time of sampling until death or censor date.

†Multivariate model additionally adjusted for tumor site (colon/rectum), time between definitive treatment and sampling, and season of blood collection. Also adjusted for surgery (yes/no) for AJCC stage I subgroup (all patients with stage II and III disease had surgery with curative intent).

$\neq$ Multivariate model additionally adjusted for body mass index and level of physical activity. 
disease in a subset of patients for whom these data were available $(\mathrm{n}=758$; chemotherapy administered to 365 patients).

\section{Time to Sampling}

Median time to sampling was 105 days after the definitive treatment (interquartile range [IQR], 53 to 200 days). A variable describing time from definitive treatment to blood sampling was created, because acute illness, surgery, and postoperative recovery may influence vitamin $\mathrm{D}$ levels. ${ }^{6}$

\section{Statistical Analysis and Survival}

Data were analyzed by using R program and survival package for $\mathrm{R}$. The associations between circulating vitamin $\mathrm{D}$ and patient characteristics were investigated by one-way analysis of variance or by $\chi^{2}$ test for categorical variables. We first examined the association between vitamin D and CRCspecific and all-cause mortality by using Kaplan-Meier survival analysis. Cox proportional hazards models were used to calculate hazard ratios (HRs), adjusting the analysis for other relevant factors. Test of the proportional hazards assumptions was performed. HRs were calculated for vitamin D tertiles, with the lowest category as the reference. To explore effect modification, we assessed the risk in an analysis stratified for cancer stage. Trend tests were calculated based on $25-\mathrm{OHD}$ as a continuous variable. $P<.05$ was considered statistically significant unless otherwise stated. Main effects of VDR polymorphisms and haplotypes and their multiplicative interaction with vitamin D on survival were assessed by using a Cox proportional hazards model.
Because four single nucleotide polymorphisms (SNPs) in the VDR gene were tested, the corrected $P$ value threshold was set to .013 for this analysis.

\section{Meta-Analysis}

We searched PubMed and Cochrane Collaboration databases for studies that investigated the relationship between circulating 25-OHD and survival in patients with colorectal cancer by using search terms "25-hydroxyvitamin D", "vitamin D", "colon cancer", "colorectal cancer", "rectal cancer", "bowel cancer", "survival", and "mortality", and we hand-searched resultant bibliographic references. We identified only six relevant studies ${ }^{13,16,27-30}$ and one recent systematic review. ${ }^{31}$ Exclusions were as follows: two studies ${ }^{13,16}$ reported analyses of the same patient cohort; one study ${ }^{16}$ used predicted rather than measured 25-OHD; and another study ${ }^{29}$ included patients with metastatic (stage IV) CRC. We performed a fixed effects meta-analysis of our data with that from the four remaining studies. ${ }^{13,27,28,30}$

\section{RESULTS}

At the time of sampling, $49.7 \%$ of patients fulfilled criteria for vitamin D deficiency (25-OHD below $10 \mathrm{ng} / \mathrm{mL}$ ), and a further $26.8 \%$ were at high risk of deficiency (10 to $16 \mathrm{ng} / \mathrm{mL}$ ). Baseline characteristics of study participants according to vitamin D deficiency status are shown
A

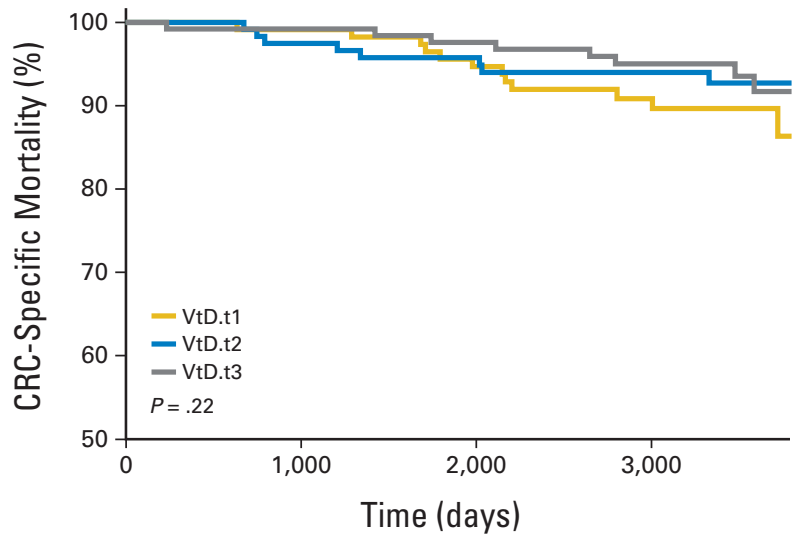

C

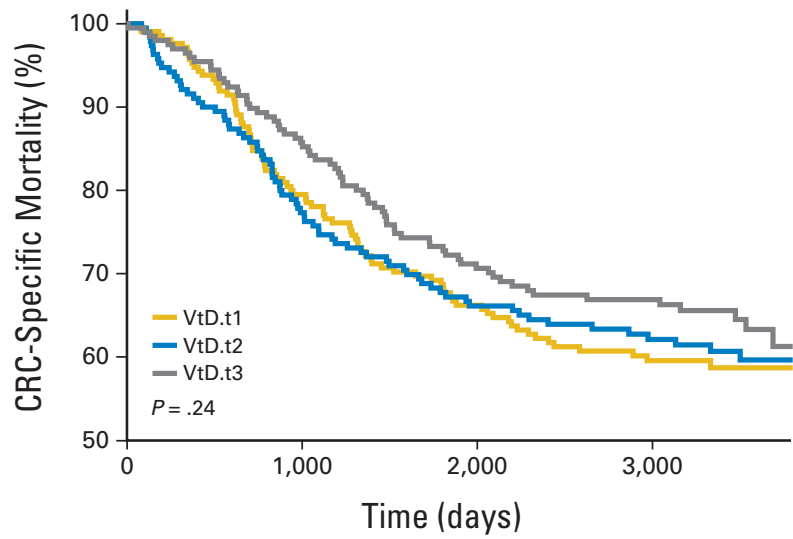

B

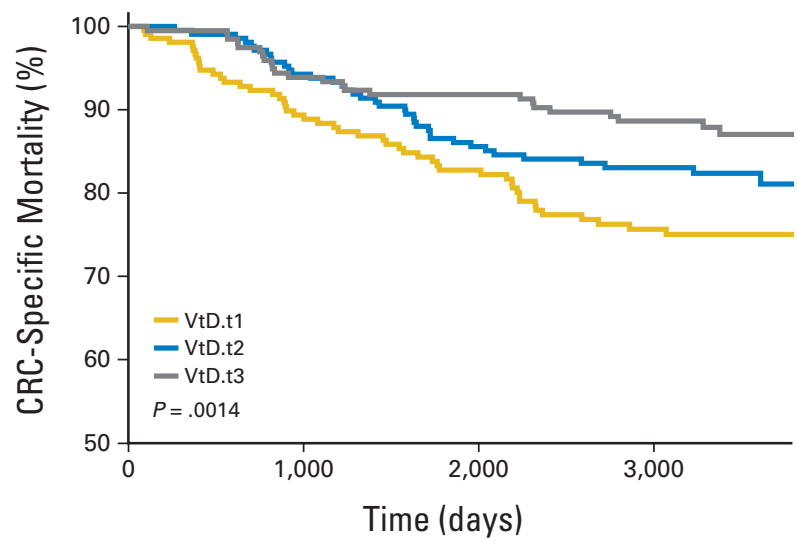

D

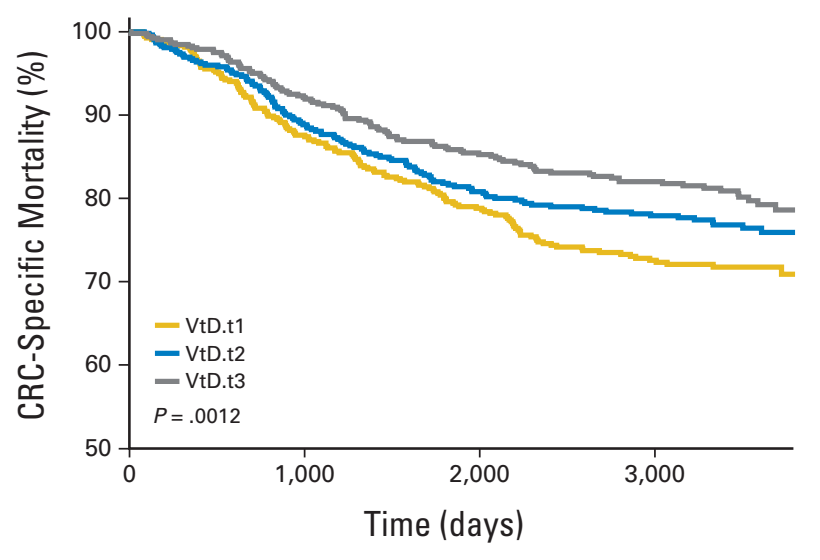

Fig 1. Colorectal cancer (CRC) -specific survival (after sampling) according to tertile of postoperative 25-hydroxyvitamin D (VtD) levels in patients with CRC. (A)

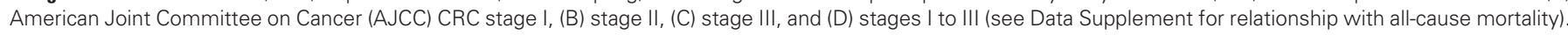

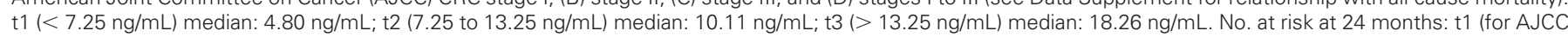

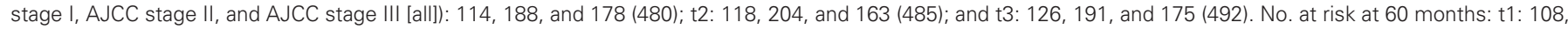
158, and 138 (404); t2: 110, 178, and 126 (414); and t3: 120, 177, and 141 (438). 
in the Data Supplement and according to tertiles in Table 1. Among the 1,598 patients, there were 12,323 person-years of follow-up, 363 deaths as a result of CRC, and 168 deaths as a result of other causes (Table 1). Median follow-up was 8.9 years (IQR, 6.0 to 9.9 years) overall and 9.6 years (IQR, 8.8 to 10.2 years) for those alive at censor date. Median survival time by stage for patients who died as a result of CRC was 5.5 years (IQR, 3.6 to 7.4 years; $\mathrm{n}=28$ ) for stage I, 3.4 years (IQR, 2.1 to 5.6 years; $\mathrm{n}=110$ ) for stage II, and 2.7 years (IQR, 1.6 to 4.5 years; $\mathrm{n}=227$ ) for stage III patients (Data Supplement).

\section{Mortality}

Higher postoperative 25-OHD levels were strongly associated with lower CRC-specific $(P=.008)$ and all-cause $(P=.003)$ mortality (Table 2). Comparing patients with May-adjusted 25-OHD levels in the highest versus the lowest tertile, the adjusted $\mathrm{HR}$ was $0.68(95 \% \mathrm{CI}$, 0.50 to 0.90 ) for CRC-specific mortality and 0.70 (95\% CI, 0.55 to 0.89 ) for all-cause mortality. Results were consistent using unadjusted 25-OHD (Data Supplement). The effect was particularly apparent for patients with stage II disease. Comparing the highest to the lowest tertile in patients with stage II CRC, the adjusted HR was 0.44 (95\% CI, 0.25 to 0.76 ) for CRC-specific mortality (Table 3). CRC-specific mortality reached $10 \%$ after 2.5 years for patients in the lowest tertile (AJCC II) and after 6.6 years for patients in the highest tertile of 25-OHD (Fig 1). Trends were similar for all-cause mortality (Data Supplement).

Analysis of deficiency categories $(<10,10$ to 16,16 to 20 , and $>20 \mathrm{ng} / \mathrm{mL}$ ) gave results consistent with those using tertiles (data not shown) and when we calculated follow-up from incidence instead of sampling date adjusting for survival before sampling.

\section{Adjuvant Chemotherapy}

The protective effect of higher 25-OHD levels was stronger for patients not receiving chemotherapy (disease stage II and III) than for those receiving chemotherapy (lowest $v$ highest tertiles; HR, 0.42; 95\% CI, 0.22 to $\left.0.80 ; P=.008 ; P_{\text {trend }}=.006\right)$. Again, the effect size was most prominent in stage II disease ( $\mathrm{HR}, 0.34 ; 95 \% \mathrm{CI}, 0.14$ to 0.81 ; Data Supplement).

\section{Meta-Analysis}

In multivariable analysis, each study showed either an association between lower mortality and higher 25-OHD levels or a nonsignificant trend with the same direction of effect (Data Supplement). In a meta-analysis of four published studies and our data, adjusted HR for CRC-specific mortality was 0.67 (95\% CI, 0.54 to 0.81 ), and it was 0.65 (95\% CI, 0.55 to 0.77; Data Supplement) for all-cause mortality.

\section{Genotype and Haplotypes at the VDR Locus}

There was no association between survival and VDR SNPs individually or with protective allele score (Table 4). However, there was evidence for gene-environment interaction effects on CRC-specific mortality between May-adjusted 25-OHD level and rs11568820 genotype $(P=.008)$ and also protective allele score $(P=.004$; Table 4 and Data Supplement for all-cause mortality). A trend toward a reduction in cancer mortality was observed for a majority of genotype subgroups (Table 5). Interestingly, if the number of protective alleles was low (two or fewer), adjusted HR for the highest tertile of May-adjusted 25-OHD was highly significant (HR, 0.46 ; $95 \% \mathrm{CI}, 0.33$ to $0.70 ; P<$ .001 ), although if there were three or more protective alleles, Mayadjusted 25-OHD was not significantly associated with survival (HR, $1.01 ; 95 \%$ CI, 0.65 to 1.58 ). Notwithstanding that dietary history is an imprecise measure of vitamin D intake, we observed a suggestive interaction between intake and rs11568820 genotype (adjusted $P=$ .09 for CRC-specific mortality; unadjusted $P=.11$ ).

Analysis of haplotypes with frequencies of more than $10 \%$ is shown in the Data Supplement. In the adjusted Cox proportional hazards model, there was no association between haplotype dose

\begin{tabular}{|c|c|c|c|c|c|c|c|}
\hline \multirow[b]{2}{*}{ SNP* } & \multirow[b]{2}{*}{ Model } & \multicolumn{3}{|c|}{ Unadjusted 25-OHD } & \multicolumn{3}{|c|}{ May-Adjusted 25-OHD } \\
\hline & & SNP & $25-\mathrm{OHD}$ & $P_{\text {interaction }}$ & SNP & 25-OHD & $P_{\text {interaction }}$ \\
\hline \multirow[t]{2}{*}{ rs7975232 } & Simple & 0.93 & 0.13 & & 0.93 & 0.18 & \\
\hline & With interaction & 0.94 & 0.47 & .88 & 0.97 & 0.47 & .99 \\
\hline \multirow[t]{2}{*}{ rs1544410 } & Simple & 0.74 & 0.11 & & 0.73 & 0.15 & \\
\hline & With interaction & 0.91 & 0.27 & .71 & 0.74 & 0.55 & .87 \\
\hline \multirow[t]{2}{*}{ rs10735810 } & Simple & 0.67 & 0.11 & & 0.65 & 0.14 & \\
\hline & With interaction & 0.76 & 0.38 & .93 & 0.44 & 0.21 & .53 \\
\hline \multirow[t]{2}{*}{ rs11568820 (AA + AG v GG) } & Simple & 0.80 & 0.10 & & 0.80 & 0.13 & \\
\hline & With interaction & 0.06 & 0.05 & .01 & 0.05 & 0.04 & .008 \\
\hline \multirow{2}{*}{$\begin{array}{l}\text { Protective alleles } \\
\leq 2 \vee 2+1\end{array}$} & Simple & 0.63 & 0.10 & & 0.60 & 0.12 & \\
\hline & With interaction & 0.04 & 0.01 & .03 & 0.008 & 0.002 & .004 \\
\hline \multicolumn{8}{|c|}{ 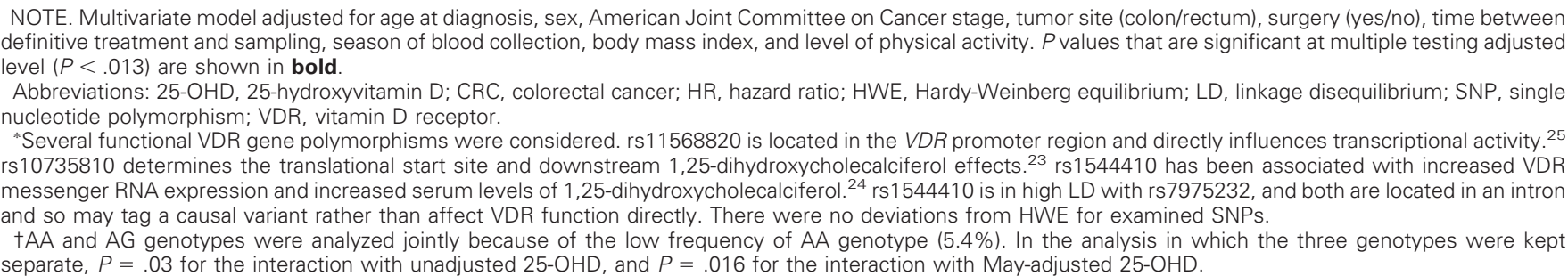 } \\
\hline
\end{tabular}




\begin{tabular}{|c|c|c|c|c|c|c|c|c|c|}
\hline \multirow[b]{3}{*}{ SNP } & \multirow[b]{3}{*}{ Genotype } & \multirow[b]{3}{*}{ Model } & \multicolumn{5}{|c|}{ Vitamin D Deficiency (estimated from May-adjusted 25-OHD) } & \multirow[b]{3}{*}{$P_{\text {trend }}$} & \multirow{3}{*}{$\begin{array}{l}\text { No. of } \\
\text { Patients }\end{array}$} \\
\hline & & & \multirow{2}{*}{$\begin{array}{c}\text { Tertile } 1 \\
(<7.25 \mathrm{ng} / \mathrm{mL}) \\
\mathrm{HR}\end{array}$} & \multicolumn{2}{|c|}{$\begin{array}{c}\text { Tertile } 2 \\
(7.25-13.25 \mathrm{ng} / \mathrm{mL})\end{array}$} & \multicolumn{2}{|c|}{$\begin{array}{c}\text { Tertile } 3 \\
(>13.25 \mathrm{ng} / \mathrm{mL})\end{array}$} & & \\
\hline & & & & $\mathrm{HR}$ & $95 \% \mathrm{Cl}$ & HR & $95 \% \mathrm{Cl}$ & & \\
\hline \multirow[t]{6}{*}{ rs7975232 } & $\mathrm{CC}$ & Unadjusted & Ref & 0.68 & 0.39 to 1.18 & 0.43 & 0.24 to 0.79 & .006 & 325 \\
\hline & & Full & Ref & 0.85 & 0.46 to 1.55 & 0.28 & 0.13 to 0.6 & .001 & 263 \\
\hline & $A C$ & Unadjusted & Ref & 0.89 & 0.63 to 1.25 & 0.86 & 0.61 to 1.22 & .41 & 807 \\
\hline & & Full & Ref & 1.05 & 0.71 to 1.54 & 1.15 & 0.77 to 1.72 & .5 & 689 \\
\hline & $A A$ & Unadjusted & Ref & 0.74 & 0.47 to 1.18 & 0.54 & 0.32 to 0.9 & .02 & 420 \\
\hline & & Full & Ref & 0.58 & 0.34 to 0.99 & 0.43 & 0.24 to 0.79 & .005 & 354 \\
\hline \multirow[t]{6}{*}{ rs11568820* } & AA $†$ & Unadjusted & Ref & 2.27 & 0.88 to 5.85 & 0.45 & 0.14 to 1.5 & .26 & 82 \\
\hline & & Full & Ref & 4.72 & 1.22 to 18.27 & 0.81 & 0.17 to 3.92 & .81 & 64 \\
\hline & $A G$ & Unadjusted & Ref & 1.06 & 0.67 to 1.68 & 1.06 & 0.67 to 1.67 & .81 & 501 \\
\hline & & Full & Ref & 1.16 & 0.7 to 1.91 & 1.04 & 0.61 to 1.75 & .89 & 423 \\
\hline & GG & Unadjusted & Ref & 0.65 & 0.47 to 0.89 & 0.54 & 0.38 to 0.76 & $<.001$ & 944 \\
\hline & & Full & Ref & 0.69 & 0.49 to 0.98 & 0.54 & 0.36 to 0.79 & .001 & 799 \\
\hline \multirow[t]{6}{*}{ rs1544410* } & $\mathbf{A A}^{\dagger}$ & Unadjusted & Ref & 0.74 & 0.41 to 1.34 & 0.64 & 0.33 to 1.23 & .16 & 258 \\
\hline & & Full & Ref & 0.55 & 0.28 to 1.09 & 0.46 & 0.21 to 1.01 & .04 & 218 \\
\hline & $A G$ & Unadjusted & Ref & 0.88 & 0.63 to 1.24 & 0.73 & 0.51 to 1.03 & .08 & 766 \\
\hline & & Full & Ref & 0.99 & 0.67 to 1.45 & 0.83 & 0.56 to 1.24 & .37 & 649 \\
\hline & GG & Unadjusted & Ref & 0.72 & 0.47 to 1.1 & 0.58 & 0.37 to 0.91 & .02 & 561 \\
\hline & & Full & Ref & 0.83 & 0.53 to 1.32 & 0.54 & 0.31 to 0.92 & .03 & 460 \\
\hline \multirow[t]{6}{*}{ rs10735810* } & AA & Unadjusted & Ref & 0.81 & 0.44 to 1.47 & 0.52 & 0.27 to 1 & .05 & 233 \\
\hline & & Full & Ref & 0.83 & 0.41 to 1.68 & 0.51 & 0.23 to 1.1 & .09 & 191 \\
\hline & $A G$ & Unadjusted & Ref & 0.8 & 0.56 to 1.15 & 0.74 & 0.51 to 1.06 & .1 & 757 \\
\hline & & Full & Ref & 0.86 & 0.58 to 1.27 & 0.67 & 0.44 to 1.01 & .05 & 636 \\
\hline & $\mathbf{G G}+$ & Unadjusted & Ref & 0.83 & 0.56 to 1.24 & 0.61 & 0.39 to 0.95 & .03 & 585 \\
\hline & & Full & Ref & 0.9 & 0.58 to 1.39 & 0.75 & 0.45 to 1.24 & .26 & 500 \\
\hline \multirow[t]{12}{*}{ VDR protective alleles } & 0,1 & Unadjusted & Ref & 0.6 & 0.34 to 1.06 & 0.4 & 0.21 to 0.74 & .003 & 302 \\
\hline & & Full & Ref & 0.67 & 0.35 to 1.3 & 0.37 & 0.17 to 0.79 & .009 & 250 \\
\hline & 2 & Unadjusted & Ref & 0.68 & 0.45 to 1.03 & 0.55 & 0.35 to 0.86 & .008 & 500 \\
\hline & & Full & Ref & 0.65 & 0.41 to 1.03 & 0.52 & 0.31 to 0.86 & .009 & 431 \\
\hline & 3 & Unadjusted & Ref & 1.1 & 0.66 to 1.82 & 1.21 & 0.73 to 2.01 & .45 & 426 \\
\hline & & Full & Ref & 1.61 & 0.92 to 2.83 & 1.46 & 0.82 to 2.62 & .17 & 357 \\
\hline & $4+$ & Unadjusted & Ref & 0.99 & 0.57 to 1.7 & 0.6 & 0.32 to 1.13 & .12 & 290 \\
\hline & & Full & Ref & 0.93 & 0.49 to 1.76 & 0.65 & 0.31 to 1.36 & .26 & 248 \\
\hline & $\leq 2$ & Unadjusted & Ref & 0.65 & 0.46 to 0.91 & 0.49 & 0.34 to 0.7 & $<.001$ & 802 \\
\hline & & Full & Ref & 0.65 & 0.45 to 0.95 & 0.46 & 0.3 to 0.7 & $<.001$ & 681 \\
\hline & $>2$ & Unadjusted & Ref & 1.05 & 0.72 to 1.52 & 0.92 & 0.62 to 1.35 & .68 & 716 \\
\hline & & Full & Ref & 1.16 & 0.77 to 1.75 & 1.01 & 0.65 to 1.58 & .92 & 605 \\
\hline $\begin{array}{l}\text { NOTE. Full model is ad } \\
\text { definitive treatment and } \\
\text { level }(P<.013) \text { are sho } \\
\text { "Included in protective } \\
\text { tProtective allele. }\end{array}$ & $\begin{array}{l}\text { ted for age a } \\
\text { mpling, seaso } \\
\text { in bold. } \\
\text { ele score calc }\end{array}$ & $\begin{array}{l}\text { liagnosis, sex, } \\
\text { of blood collect } \\
\text { ation. }\end{array}$ & $\begin{array}{l}\text { can Joint Comm } \\
\text { dy mass index, }\end{array}$ & el of & $\begin{array}{l}\text { stage, tumor } \\
\text { cal activity. R }\end{array}$ & $s$ that & $\begin{array}{l}\text { tum), surger } \\
\text { significant at }\end{array}$ & $\begin{array}{l}\text { es/no), } \\
\text { ultiple te }\end{array}$ & $\begin{array}{l}\text { between } \\
\text { g adjusted }\end{array}$ \\
\hline
\end{tabular}

(alone) and survival (Data Supplement). However, after including an interaction term in the model, there was an interaction between dose of GAGC haplotype and May-adjusted vitamin D. This interaction was highly significantly associated with overall survival, even after accounting for multiple testing $(P=.008)$.

\section{DISCUSSION}

In this prospective cohort study of 1,598 patients sampled after treatment for stage I to III CRC, we show that higher plasma 25-OHD level is associated with lower cancer-specific and all-cause mortality. We assayed plasma total 25-OHD, the best biomarker of both dietary intake and sunlight exposure. The interaction between
25-OHD and genetic variation at the VDR locus in relation to survival provides additional evidence implicating the vitamin $\mathrm{D}$ pathway and provides support for a causal relationship (see the Data Supplement for a discussion of causality). The magnitude of effect was substantial and clinically important. Mortality was about one third lower in the patient group with the highest compared with the lowest plasma 25-OHD tertiles. The direction of protective effect was consistent across different strata of patients. CRCspecific mortality was $20 \%$ at 5 years in patients with the lowest plasma 25-OHD tertile, and 10 years elapsed before mortality reached $20 \%$ in those with the highest tertile. There was a similar differential in all-cause mortality between plasma tertile groups (20\% mortality after 3.5 and 6.0 years). 
Because of Scotland's northern latitude, vitamin D deficiency is highly prevalent in the Scottish population ${ }^{4}$ and, unsurprisingly, this is reflected in the patients with CRC studied here. However, even within this narrow, deficient range, we have shown that vitamin $\mathrm{D}$ has a protective effect from death after a diagnosis of CRC. This suggests that plasma 25-OHD assayed postoperatively may have utility as a biomarker for survival in patients without evidence of systemic metastases. Furthermore, the gene-environment interaction between genetic variation at the VDR locus and vitamin $\mathrm{D}$ level suggests that vitamin $D$ may actively protect from death, rather than merely reflecting tumor aggression and an inevitable outcome. Although the evidence presented here linking plasma 25-OHD level with outcome is persuasive, there is now a pressing need for prospective randomized trials to establish definitively whether dietary vitamin D supplementation reduces cancer-specific and all-cause mortality following a diagnosis of CRC.

All published studies to date have a fundamental methodologic limitation: 25-OHD concentration was not determined in cancer survivors but was instead measured years before cancer diagnosis, ${ }^{13,27,30}$ perioperatively, ${ }^{28}$ or was predicted from the determinants of $25-\mathrm{OHD}$ concentration. ${ }^{16}$ We designed this study to investigate whether vitamin D deficiency contributes to survival outcome in a wellcharacterized cohort in which plasma 25-OHD was measured after CRC diagnosis and surgical treatment. Thus, to the best of our knowledge, this is the first study to examine the effect of postoperative vitamin $\mathrm{D}$ levels on survival in patients with $\mathrm{CRC}$ and the first to investigate gene-environment interaction between vitamin $\mathrm{D}$ level and genetic variation at the VDR gene locus.

This study has some limitations. One single measurement of 25-OHD was taken. Although this is likely to reduce statistical power, it is unlikely to bias findings. In this population, 25-OHD concentrations are generally low, preventing us from systematically examining the effect of higher concentrations. The time period between cancer treatment and 25-OHD sampling levels was not constant (although there was no detectable association between time interval to sampling and 25-OHD levels or outcome). The limited number of SNPs in the analysis may reduce the accuracy of inferred haplotypes. We cannot exclude the possibility that low 25-OHD is associated with other predictors of poor prognosis because this was an observational study.
Evidence from epidemiologic, preclinical, and clinical studies indicates that vitamin D (and analogs) might have application as therapeutic agents in patients with cancer following a diagnosis because their administration can activate apoptotic pathways, ${ }^{33}$ inhibit angiogenesis, ${ }^{34,35}$ and can have prodifferentiative ${ }^{36}$ and antiproliferative $^{37}$ effects (Data Supplement). ${ }^{38}$ Recent randomized clinical trials of the effects of supplemental vitamin D report a reduction in tumorpromoting inflammation biomarkers with vitamin $\mathrm{D}_{3}$ supplementation, ${ }^{39}$ decreased oxidative DNA damage, ${ }^{40}$ and modification of the $A P C / \beta$-catenin pathway $^{41}$ in the normal mucosa of patients with colorectal adenoma, further highlighting the need to explore vitamin $\mathrm{D}$ as a preventative and therapeutic anticancer agent. ${ }^{38}$

In this large study, we report for the first time an association between mortality following a diagnosis of CRC and an interaction between GAGC haplotype dose and vitamin D. Plasma 25-OHD, along with genotype at the $V D R$ locus, has potential utility as a prognostic biomarker. In conclusion, our findings suggest a causal relationship between vitamin $\mathrm{D}$ and survival outcome in patients with cancer. Hence, there is now a compelling case for appropriately designed and adequately powered randomized clinical trials aimed at testing whether actively supplementing the diet of patients recently diagnosed with CRC with vitamin $\mathrm{D}$ can have a favorable impact on survival.

\section{AUTHORS' DISCLOSURES OF POTENTIAL CONFLICTS OF INTEREST}

The author(s) indicated no potential conflicts of interest.

\section{AUTHOR CONTRIBUTIONS}

Conception and design: Lina Zgaga, Evropi Theodoratou, Susan M. Farrington, Harry Campbell, Malcolm G. Dunlop

Financial support: Malcolm G. Dunlop, Harry Campbell

Collection and assembly of data: Lina Zgaga, Evropi Theodoratou, Susan M. Farrington, Farhat V.N. Din, Li Yin Ooi, Susan Johnston, Albert Tenesa, Harry Campbell, Malcolm G. Dunlop

Data analysis and interpretation: Lina Zgaga, Dominik Glodzik, Susan M. Farrington, Farhat V.N. Din, Albert Tenesa, Harry Campbell, Malcolm G. Dunlop

Manuscript writing: All authors

Final approval of manuscript: All authors

\section{REFERENCES}

1. Schöttker B, Haug U, Schomburg L, et al: Strong associations of 25-hydroxyvitamin D concentrations with all-cause, cardiovascular, cancer, and respiratory disease mortality in a large cohort study. Am J Clin Nutr 97:782-793, 2013

2. Ferlay J, Shin HR, Bray F, et al: Estimates of worldwide burden of cancer in 2008: GLOBOCAN 2008. Int J Cancer 127:2893-2917, 2010

3. Giovannucci E: The epidemiology of vitamin $D$ and cancer incidence and mortality: A review (United States). Cancer Causes Control 16:83-95, 2005

4. Zgaga $L$, Theodoratou $E$, Farrington $S M$, et al: Diet, environmental factors, and lifestyle underlie the high prevalence of vitamin D deficiency in healthy adults in Scotland, and supplementation reduces the proportion that are severely deficient. J Nutr 141:1535-1542, 2011

5. Calvo MS, Whiting SJ, Barton CN: Vitamin D intake: A global perspective of current status. J Nutr 135:310-316, 2005

6. Reid D, Toole BJ, Knox S, et al: The relation between acute changes in the systemic inflammatory response and plasma 25-hydroxyvitamin D concentrations after elective knee arthroplasty. Am J Clin Nutr 93:1006-1011, 2011

7. Touvier M, Chan DS, Lau R, et al: Metaanalyses of vitamin D intake, 25-hydroxyvitamin D status, vitamin D receptor polymorphisms, and colorectal cancer risk. Cancer Epidemiol Biomarkers Prev 20:1003-1016, 2011

8. Zgaga L, Agakov F, Theodoratou E, et al: Model selection approach suggests causal association between 25-hydroxyvitamin D and colorectal cancer. PLoS One 8:e63475, 2013
9. Theodoratou $E$, Farrington $S M$, Tenesa $A$, et al: Modification of the inverse association between dietary vitamin $D$ intake and colorectal cancer risk by a Fokl variant supports a chemoprotective action of Vitamin D intake mediated through VDR binding. Int J Cancer 123:2170-2179, 2008

10. Theodoratou E, Palmer T, Zgaga L, et al: Instrumental variable estimation of the causal effect of plasma 25-hydroxy-vitamin D on colorectal cancer risk: A mendelian randomization analysis. PLoS One 7:e37662, 2012

11. Garland CF, Garland FC: Do sunlight and vitamin $D$ reduce the likelihood of colon cancer? Int J Epidemiol 9:227-231, 1980

12. Moan J, Porojnicu AC, Robsahm TE, et al: Solar radiation, vitamin $D$ and survival rate of colon cancer in Norway. J Photochem Photobiol B 78:189-193, 2005

13. $\mathrm{Ng} \mathrm{K}$, Meyerhardt JA, Wu K, et al: Circulating 25-hydroxyvitamin d levels and survival in patients 
with colorectal cancer. J Clin Oncol 26:2984-2991, 2008

14. Grant WB: The likely role of vitamin D from solar ultraviolet-B irradiance in increasing cancer survival. Anticancer Res 26:2605-2614, 2006

15. Lim HS, Roychoudhuri R, Peto J, et al: Cancer survival is dependent on season of diagnosis and sunlight exposure. Int J Cancer 119:1530-1536, 2006

16. $\mathrm{Ng} \mathrm{K}$, Wolpin BM, Meyerhardt JA, et al: Prospective study of predictors of vitamin $D$ status and survival in patients with colorectal cancer. $\mathrm{Br} \mathrm{J}$ Cancer 101:916-923, 2009

17. Maalmi H, Ordóñez-Mena JM, Schöttker B, et al: Serum 25-hydroxyvitamin D levels and survival in colorectal and breast cancer patients: Systematic review and meta-analysis of prospective cohort studies. Eur J Cancer 50:1510-1521, 2014

18. Ross AC, Manson JE, Abrams SA, et al: The 2011 report on dietary reference intakes for calcium and vitamin $D$ from the Institute of Medicine: What clinicians need to know. J Clin Endocrinol Metab 96:53-58, 2011

19. Seamans KM, Cashman KD: Existing and potentially novel functional markers of vitamin $D$ status: A systematic review. Am J Clin Nutr 89:1997S-2008S, 2009

20. Theodoratou E, Kyle J, Cetnarskyj R, et al: Dietary flavonoids and the risk of colorectal cancer. Cancer Epidemiol Biomarkers Prev 16:684-693, 2007

21. Knox S, Harris J, Calton L, et al: A simple automated solid-phase extraction procedure for measurement of 25-hydroxyvitamin D3 and D2 by liquid chromatography-tandem mass spectrometry. Ann Clin Biochem 46:226-230, 2009

22. Colin EM, Weel AE, Uitterlinden AG, et al: Consequences of vitamin $D$ receptor gene polymorphisms for growth inhibition of cultured human peripheral blood mononuclear cells by 1, 25dihydroxyvitamin D3. Clin Endocrinol (Oxf) 52:211216, 2000

23. Uitterlinden AG, Fang $Y$, Van Meurs JB, et al: Genetics and biology of vitamin D receptor polymorphisms. Gene 338:143-156, 2004
24. Staal $A$, van Wijnen AJ, Birkenhäger JC, et al: Distinct conformations of vitamin $D$ receptor/retinoid $X$ receptor-alpha heterodimers are specified by dinucleotide differences in the vitamin D-responsive elements of the osteocalcin and osteopontin genes. Mol Endocrinol 10:1444-1456, 1996

25. Yamamoto $H$, Miyamoto $K$, Li B, et al: The caudal-related homeodomain protein $\mathrm{Cdx}-2$ regulates vitamin $D$ receptor gene expression in the small intestine. J Bone Miner Res 14:240-247, 1999

26. Browning SR, Browning BL: Rapid and accurate haplotype phasing and missing-data inference for whole-genome association studies by use of localized haplotype clustering. Am J Hum Genet 81:1084-1097, 2007

27. Fedirko V, Riboli E, Tjønneland A, et al: Prediagnostic 25-hydroxyvitamin D, VDR and CASR polymorphisms, and survival in patients with colorectal cancer in western European populations. Cancer Epidemiol Biomarkers Prev 21:582-593, 2012

28. Mezawa $H$, Sugiura $T$, Watanabe $M$, et al: Serum vitamin D levels and survival of patients with colorectal cancer: Post-hoc analysis of a prospective cohort study. BMC Cancer 10:347, 2010

29. Ng K, Sargent DJ, Goldberg RM, et al: Vitamin D status in patients with stage IV colorectal cancer: Findings from Intergroup trial N9741. J Clin Oncol 29:1599-1606, 2011

30. Tretli S, Schwartz GG, Torjesen PA, et al: Serum levels of 25-hydroxyvitamin D and survival in Norwegian patients with cancer of breast, colon, lung, and lymphoma: A population-based study. Cancer Causes Control 23:363-370, 2012

31. Pilz S, Kienreich K, Tomaschitz A, et al: Vitamin D and cancer mortality: Systematic review of prospective epidemiological studies. Anticancer Agents Med Chem 13:107-117, 2013

32. Tenesa A, Campbell H, Theodoratou E, et al: Common genetic variants at the MC4R locus are associated with obesity, but not with dietary energy intake or colorectal cancer in the Scottish population. Int J Obes (Lond) 33:284-288, 2009

33. Fedirko V, Bostick RM, Flanders WD, et al: Effects of vitamin $D$ and calcium supplementation on markers of apoptosis in normal colon mucosa: $A$ randomized, double-blind, placebo-controlled clinical trial. Cancer Prev Res (Phila) 2:213-223, 2009

34. Fernandez-Garcia NI, Palmer HG, Garcia M, et al: 1alpha,25-Dihydroxyvitamin D3 regulates the expression of Id 1 and Id 2 genes and the angiogenic phenotype of human colon carcinoma cells. Oncogene 24:6533-6544, 2005

35. Iseki $\mathrm{K}$, Tatsuta $\mathrm{M}$, Uehara $\mathrm{H}$, et al: Inhibition of angiogenesis as a mechanism for inhibition by 1alphahydroxyvitamin D3 and 1,25-dihydroxyvitamin D3 of colon carcinogenesis induced by azoxymethane in Wistar rats. Int J Cancer 81:730-733, 1999

36. Pálmer HG, González-Sancho JM, Espada J, et al: Vitamin $D(3)$ promotes the differentiation of colon carcinoma cells by the induction of E-cadherin and the inhibition of beta-catenin signaling. J Cell Biol 154:369-387, 2001

37. Fedirko V, Bostick RM, Flanders WD, et al: Effects of vitamin $d$ and calcium on proliferation and differentiation in normal colon mucosa: A randomized clinical trial. Cancer Epidemiol Biomarkers Prev 18:2933-2941, 2009

38. Deeb KK, Trump DL, Johnson CS: Vitamin D signalling pathways in cancer: Potential for anticancer therapeutics. Nat Rev Cancer 7:684-700, 2007

39. Hopkins MH, Owen J, Ahearn T, et al: Effects of supplemental vitamin $\mathrm{D}$ and calcium on biomarkers of inflammation in colorectal adenoma patients: A randomized, controlled clinical trial. Cancer Prev Res (Phila) 4:1645-1654, 2011

40. Fedirko V, Bostick RM, Long Q, et al: Effects of supplemental vitamin $D$ and calcium on oxidative DNA damage marker in normal colorectal mucosa: A randomized clinical trial. Cancer Epidemiol Biomarkers Prev 19:280-291, 2010

41. Ahearn TU, Shaukat A, Flanders WD, et al: A randomized clinical trial of the effects of supplemental calcium and vitamin D3 on the APC/beta-catenin pathway in the normal mucosa of colorectal adenoma patients. Cancer Prev Res (Phila) 5:12471256, 2012 


\section{GLOSSARY TERMS}

1,25-dihydroxycholecalciferol [1,25(OH)2D]: a steroid hormone (also known as calcitriol) that functions as the physiologically most active form of vitamin D. It acts in an autocrine and paracrine manner and binds to the vitamin D receptor to regulate calcium homeostasis and bone growth and mineralization, among other cellular processes.

APC: a tumor suppressor gene. Mutations in the APC gene are responsible for familial adenomatous polyposis (germline mutations) or sporadic (somatic mutations) colorectal tumors. The gene product is known to interact with adherens junction proteins, a- and b-catenins, suggesting a role in cell adhesion.

American Joint Committee on Cancer (AJCC)/ Union for International Cancer Control (UICC) TNM staging: a cancer staging system that describes the extent of cancer in a patient's body. "T" describes the size of the tumor and whether it has invaded nearby tissue; " $\mathrm{N}$ " describes regional lymph nodes that are involved; "M" describes distant metastasis (spread of cancer from one body part to another). The TNM Classification of Malignant Tumours was developed and maintained by the UICC to achieve consensus on one globally recognized standard for classifying the extent of spread of cancer. The TNM classification was also used by the AJCC. In 1987, the UICC and AJCC staging systems were unified into a single staging system. Prognosis of a patient is defined by TNM classification.

angiogenesis: the process involved in the generation of new blood vessels. Although this is a normal process that naturally occurs and is controlled by so-called on and off switches, blocking tumor angiogenesis (antiangiogenesis) disrupts the blood supply to tumors, thereby preventing tumor growth. apoptosis: also called programmed cell death. Apoptosis is a signaling pathway that leads to cellular suicide in an organized manner. Several factors and receptors are specific to the apoptotic pathway. The net result is that cells shrink and develop blebs on their surface, and their DNA undergoes fragmentation.

$\boldsymbol{\beta}$-catenin: originally identified as a component of cell-cell adhesion complexes composed of cadherins and actin. $\beta$-catenin has now been shown to be a downstream signaling molecule in the Wnt signaling pathway.

Cox proportional hazards regression model: a statistical model for regression analysis of censored survival data, examining the relationship of censored survival distribution to one or more covariates. This model produces a baseline survival curve, covariate coefficient estimates with their standard errors, risk ratios, 95\% CIs, and significance levels.

genetic polymorphisms: a genetic variant seen in at least $1 \%$ of the population. Because proteins are gene products, their polymorphisms reflect allelic differences in the gene. The advent of restriction enzymes, which digest DNA to fragments based on sequence specificity, has ushered in an era of restriction fragment length polymorphisms in which changes in DNA sequences manifest as restriction fragments of different sizes when cleaved with a specific restriction enzyme. Polymorphisms are used in tissue typing, in determining disease, in pharmacogenetics, and in assessing genetic diversity. 


\section{Acknowledgment}

We acknowledge the excellent technical support from Marion Walker and Stuart Reid. We are grateful to Ruth Wilson, Donna Markie, and all those who continue to contribute to recruitment, data collection, and data curation for the Study of Colorectal Cancer in Scotland studies. In addition to all consultant colorectal surgeons who provided stage and other data on their patients, we are also indebted to the chairs and offices of the Managed Clinical Networks throughout Scotland who contributed substantially to clinicopathologic data and staging information. We acknowledge the expert support on sample preparation from the Genetics Core of the Edinburgh Wellcome Trust Clinical Research Facility. 